\title{
Magnetic Resonance Spectroscopy Shows Increased Brain Glutamine in Ornithine Carbamoyl Transferase Deficiency
}

\author{
A. CONNELly, J. H. CROSS, D. G. GADIAN, J. V. HUNTER, F. J. KIRKHAM, AND \\ J. V. LEONARD \\ Institute of Child Health and The Hospital for Sick Children, London WC1, United Kingdom
}

\begin{abstract}
We have performed localized in vivo proton magnetic resonance spectroscopy on two females with ornithine carbamoyl transferase deficiency during episodes of acute hyperammonemic encephalopathy with focal neurologic abnormalities. Spectra obtained from $2 \times 2 \times 2 \mathrm{~cm}$ cubic volumes at relatively long (135-ms) echo times contain additional signals that are characteristic of glutamine and indicate that glutamine is present in very high concentrations in the brain. The findings are consistent with the hypothesis that intracerebral accumulation of glutamine contributes to the encephalopathy associated with hyperammonemia. In one of the children, spectra obtained after treatment showed a marked decrease in the glutamine signals. (Pediatr Res 33: 77-81, 1993)
\end{abstract}

\section{Abbreviations}

${ }^{1} \mathrm{H}$ MRS, proton magnetic resonance spectroscopy

OCT, ornithine carbamoyl transferase

TE, echo time; time between $90^{\circ}$ pulse and echo maximum

TR, repetition time; time between successive date acquisitions

$\mathrm{TI}$, inversion time; time between inversion and $90^{\circ}$ pulses in inversion recovery sequence

T1, spin-lattice relaxation time

$\mathrm{T} 2$, spin-spin relaxation time

NAA, $\mathbf{N}$-acetylaspartate

$\mathrm{Cr}$, creatine + phosphocreatine

Cho, choline-containing compounds

MR, magnetic resonance

$\mathrm{T}$, tesla

OCT deficiency is one of the five inherited disorders of the urea cycle (1). Affected individuals are prone to recurrent encephalopathy associated with hyperammonemia (2). The mechanism responsible for this encephalopathy has been the subject of wide debate. The possibilities, which are not mutually exclusive, include alterations in energy metabolism $(3,4)$, neurotransmitter imbalance (5), astrocytic swelling $(1,6)$, seizures $(7)$, and changes in cerebral blood flow and intracranial pressure (8-10), but many of these phenomena could be secondary to the effects of glutamine, to which ammonia is converted, rather than directly to ammonia itself $(1,11)$. Measurement of glutamine concentrations in the brain in vivo during hyperammonemic encephalopathy, however, has proved difficult.

The noninvasive detection of elevated brain glutamine by ${ }^{1} \mathrm{H}$

Received January 31, 1992; accepted September 2, 1992.

Correspondence and reprint requests: Dr. A. Connelly, NMR Unit, The Hospital for Sick Children, Great Ormond Street, London WCI, UK.
MRS has previously been documented in experimentally induced hyperammonemia (12-14). However, these studies were carried out in small animals at field strengths that are much higher than those used for clinical studies. Because of the relatively complex MR characteristics of the glutamine signals, and because of spectral overlap with signals from other metabolites, the unambiguous detection of brain glutamine in patients, using field strengths of 1.5-2 T, poses difficulties. Kreis et al. (15) recently reported the observation by ${ }^{1} \mathrm{H}$ MRS of brain glutamine in patients with chronic hepatic encephalopathy, but these studies used short TE, which imposes considerable demands on machine performance.

We report the detection of brain glutamine in two children with OCT deficiency, using ${ }^{1} \mathrm{H}$ MRS with longer TE such as are more commonly used in clinical studies. We show that brain glutamine accumulates to very high concentrations in these children and also that a reduction in cerebral glutamine can be seen after treatment. Our results support the view that the encephalopathy associated with hyperammonemia may be related to the concentration of brain glutamine.

\section{PATIENTS AND METHODS}

Patients. Case 1. This girl had been under investigation at the referring hospital since the age of 6 mo for failure to thrive and nocturnal vomiting associated with irritability. At the age of 9 mo, over a period of $48 \mathrm{~h}$, she developed a left hemiparesis. On examination, her weight was below the 3 rd percentile for her age, and she had signs of a left hemiparesis and left facial palsy. She had lost sitting balance previously áchieved at 6 mo. X-ray computed tomography showed a large low-density area in the anterior two thirds of the right cerebral hemisphere. The plasma ammonia concentration $(220 \mu \mathrm{mol} / \mathrm{L}$, normal $<50 \mu \mathrm{mol} / \mathrm{L})$ was raised, as was that of alanine, glutamine, and aspartate aminotransferase $(170 \mathrm{U} / \mathrm{L}$, normal $<60 \mathrm{U} / \mathrm{L})$. The diagnosis of OCT deficiency was confirmed by the increased urinary orotic acid $(18.9 \mu \mathrm{mol} / \mathrm{mmol}$ creatinine, normal $<1.5 \mu \mathrm{mol} / \mathrm{mmol})$. ' $\mathrm{H}$ MRS of the urine confirmed high alanine, glutamine, and glycine and an elevated orotic acid. She was treated with a lowprotein diet, sodium benzoate, and arginine, and she improved clinically. After $6 \mathrm{~d}$ of treatment, plasma ammonia was $66 \mu \mathrm{mol} /$ L. On review at the age of $13 \mathrm{mo}$, she had made good developmental progress. She was pulling to stand and walking with one hand supported, but she still had a mild left hemiparesis with sensory inattention. Parents reported an improvement in her mood, and there had been good weight gain.

Case 2. Case 2 initially presented at $5 \mathrm{mo}$ of age with failure to thrive. Vomiting and irritability continued until 17 mo when she was admitted with a left hemiparesis, and she was clearly developmentally delayed. Computed tomography scan at this time showed decreased attenuation in the right hemisphere. She had hyperammonemia (plasma ammonia $236 \mu \mathrm{mol} / \mathrm{L}$ ) with 
raised plasma glutamine $(1152 \mu \mathrm{mol} / \mathrm{L})$ and alanine $(843 \mu \mathrm{mol} /$ L). OCT deficiency was confirmed by enzyme studies on liver biopsy (OCT activity $343 \mu \mathrm{mol} / \mathrm{g} / \mathrm{h}$, normal $>3000$ ). She improved and remained stable on a low-protein diet and sodium benzoate until aged $11 \mathrm{y}$ when she presented with a further episode of encephalopathy with cortical blindness (plasma ammonia $230 \mathrm{~m} / \mathrm{L}$, plasma glutamine $1092 \mu \mathrm{mol} / \mathrm{L}$ ). Visual evoked responses from the midoccipital region were abnormal, and the posterior temporal components were asymmetric with lower amplitude on the left.

\section{MATERIALS AND METHODS}

A commercial 1.5-T whole-body system (Magnetom, Siemens, Middlesex, UK) was used with a standard quadrature head coil. Both patients were studied under sedation using a protocol based on age and weight (16). Ethical approval was granted by the Ethical Committee at the Hospital for Sick Children, London. Imaging was carried out using a double-echo short TI inversion recovery sequence $(\mathrm{TR}=4 \mathrm{~s}, \mathrm{TI}=145 \mathrm{~ms}$, and $\mathrm{TE}=23 \mathrm{~ms}$ and $85 \mathrm{~ms}$ ) (17). An asymmetric field-of-view technique was used to reduce imaging time. MR angiography was performed using a three-dimensional time-of-flight technique. A $256 \times 256$ $\times 32$ matrix and a $6-\mathrm{cm}$ excitation slab thickness were used, giving a resolution in the $3 \mathrm{rd}$ dimension of $1.9 \mathrm{~mm}$ and an inplane resolution of $0.8 \mathrm{~mm}(\mathrm{TR}=0.04 \mathrm{~s}, \mathrm{TE}=12 \mathrm{~ms}$, flip angle $=25^{\circ}$ ). A maximum intensity projection procedure was applied to the three-dimensional data set to produce the two-dimensional angiograms.

Using the double-echo short TI inversion recovery images as a guide, 8 -mL $(2 \times 2 \times 2 \mathrm{~cm})$ volumes of interest were chosen from which to acquire spectra. Spatial localization was effected using a 90-180-180 spin-echo technique (18) with the three selective radiofrequency pulses applied in the presence of orthogonal gradients of $2 \mathrm{mT} / \mathrm{m}$. Water suppression was achieved by preirradiation of the water resonance using a $90^{\circ}$ gaussian pulse with a $60-\mathrm{Hz}$ band width followed by a spoiler gradient. Parameters of TR $=1600 \mathrm{~ms}$ and $\mathrm{TE}=135 \mathrm{~ms}$ were used in both patients. After global and local shimming and optimization of the water-suppression pulse, spectra were acquired in two to four blocks of 128 scans. The time-domain data were corrected for eddy current-induced phase modulation using non-water-suppressed data as a reference (19). Exponential multiplication corresponding to $1-\mathrm{Hz}$ line broadening was carried out before Fourier transformation, and a cubic spline baseline correction was performed.

Quantification of brain glutamine concentration. The measurement of absolute concentrations by ${ }^{1} \mathrm{H}$ MRS is not straightforward, as the signal intensities are influenced not only by metabolite concentrations, but also by the relaxation times $\mathrm{T} 1$ and T2, the effects of phase modulation in coupled spin systems when using spin-echo sequences, and the effects of loading on the radiofrequency coil. In the present studies, we have used the following procedure to obtain lower limits for the concentration of brain glutamine.

Localized spectra were obtained from a $2 \times 2 \times 2 \mathrm{~cm}$ region within a phantom containing $40 \mathrm{mM}$ glutamine and $10 \mathrm{mM}$ creatine in $99 \%$ deuterium oxide. The same pulse sequence was used as for the in vivo studies, with $\mathrm{TE}=135 \mathrm{~ms}$ but with a TR value of $40 \mathrm{~s}$ to allow full longitudinal recovery of the glutamine signals between scans. By comparing the signal intensities obtained in vivo with those obtained from the phantom, an estimate of the concentration in vivo can be obtained, provided that corrections are made for any difference in coil loading and for the effects of relaxation. As described previously (20), the effects of coil loading on signal intensities were corrected for by multiplying the signal intensities by the $90^{\circ}$ pulse voltage for each individual study. However, corrections for relaxation time effects were not feasible, as it was not practical in the in vivo examination to make all the necessary measurements. Both the T1 and T2 relaxation times will be shorter in vivo than those in solution, although it is unlikely that the TR of $1600 \mathrm{~ms}$ used in vivo is sufficiently long to allow complete longitudinal relaxation. However, because both partial saturation due to short TR and increased signal loss due to short $\mathrm{T} 2$ will result in decreased signal in vivo compared with the fully relaxed phantom sample, the measured concentration in vivo will be a lower limit of the actual glutamine concentration.

Concentrations of glutamine may be calculated using either the $\mathrm{CH}$ or $\mathrm{CH}_{2}$ signals. In the case of the $\mathrm{CH}_{2}$ signal, it is difficult to measure the area because of the complex phase modulation of this signal, and therefore comparisons were made on the basis of maximum peak-to-peak height after correcting the line widths of the phantom signals to make them similar to those seen in vivo. For each spectrum, the concentrations of glutamine measured on the basis of the $\mathrm{CH}$ signal area, $\mathrm{CH}$ signal height, and $\mathrm{CH}_{2}$ signal height were similar to each other, and the mean of the three measurements is given.

\section{RESULTS}

1. MR imaging. Case 1 had combined imaging/spectroscopy examinations at the time of presentation, $1 \mathrm{wk}$ after initiation of treatment and finally after 4 mo of treatment. Images from the first and third examinations are shown in Figure $1 A$ and $B$, and the regions from which spectra were obtained are indicated by the superimposed boxes. The first examination showed high signal throughout the entire right cerebral hemisphere, and there was a midline shift to the left indicating swelling of the right hemisphere. MR angiography (Fig. 2) was normal on the left. The right internal carotid and middle and anterior cerebral arteries were patent, but there were a number of prominent, probably dilated, superficial vessels with some displacement of the intrasylvian vessels as a result of the cerebral swelling. The subsequent scans showed less swelling with the final scan suggesting early right-sided atrophy.

Case 2 had one imaging investigation at the time of her second presentation with encephalopathy and occipital blindness. This showed atrophy of the right hemisphere with altered signal from the right frontal and parieto-occipital cortex.

2. MR spectroscopy. For comparison with the spectra obtained from the two patients with OCT deficiency, Figure 3 shows a normal spectrum from the occipital white matter of a 12-mo-old girl. The dominant contributions to the spectra are from NAA, $\mathrm{Cr}$, and Cho.

Figure $4 A$ and $B$ shows ${ }^{1} \mathrm{H}$ MRS spectra obtained from case 1 , both from the apparently abnormal area on the right and from the more normal left hemisphere. The abnormal region shows very low NAA, Cr, and Cho signals consistent with a major loss of cells of all types. The spectra from both regions show an abnormal signal at $3.76 \mathrm{ppm}$, and additional abnormal phasemodulated signals are observed between 2.0 and $2.5 \mathrm{ppm}$. These signals are together characteristic of glutamine (at TE of $135 \mathrm{~ms}$ ) as confirmed by the spectrum of a solution containing creatine and glutamine shown in Figure $4 C$. In case 1, spectra obtained after treatment showed a marked decrease in the glutamine signals. Glutamine peaks were also seen in the spectra obtained from case 2.

As described in the Materials and Methods section, comparisons with the data from the model solution enabled us to obtain lower limits for the concentrations of brain glutamine. The values obtained for case 1 were $20 \mathrm{mmol} / \mathrm{kg}$ wet weight for the abnormal area and $11 \mathrm{mmol} / \mathrm{kg}$ wet weight for the contralateral region. For patient 2 , the values were $13 \mathrm{mmol} / \mathrm{kg}$ wet weight and 7.5 $\mathrm{mmol} / \mathrm{kg}$ wet weight in the two selected regions (left and right occipital white matter, respectively).

\section{DISCUSSION}

Recurrent encephalopathy associated with hyperammonemia is common in individuals with OCT deficiency. Focal neurologic 

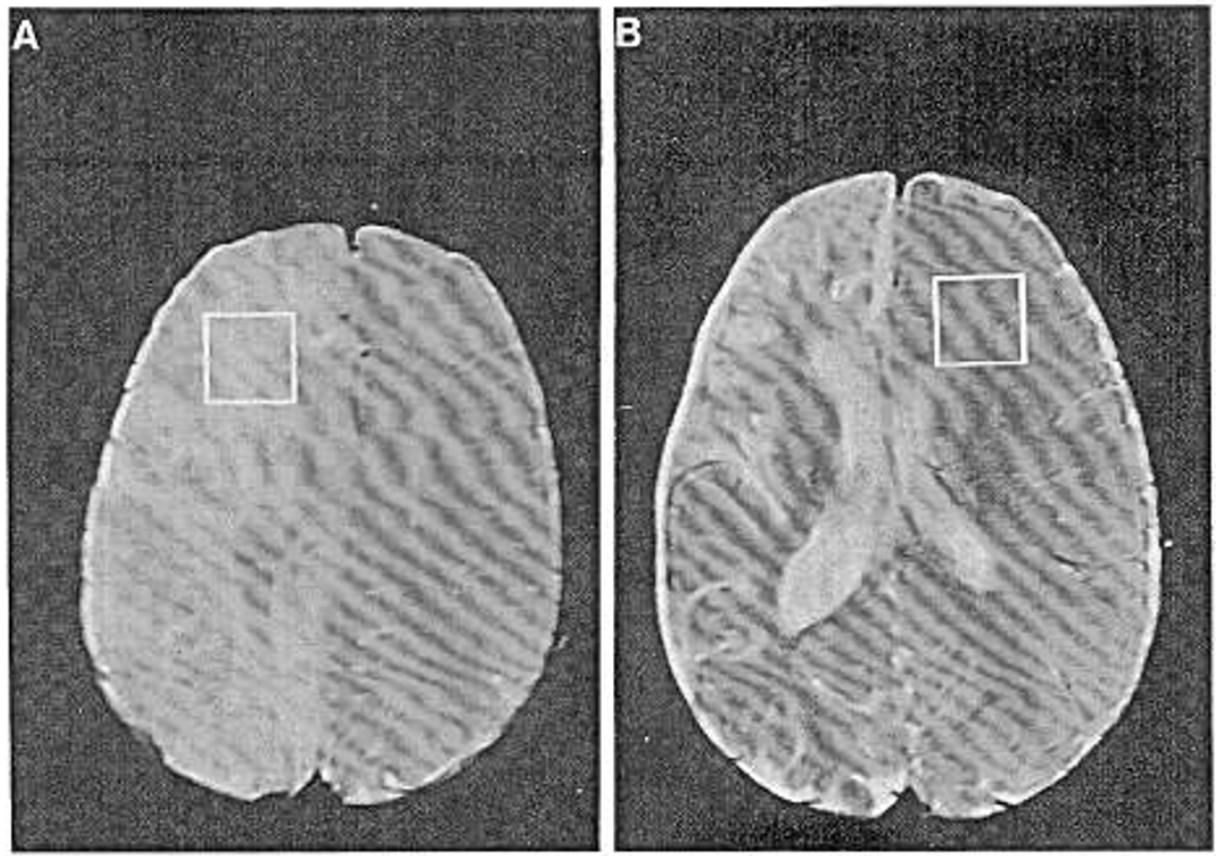

Fig. 1. MR images of the brain of case 1 at the time of presentation $(A)$, and 4 mo into treatment $(B)$. The boxes indicate the position of the 8 $\mathrm{mL}$ cubic volumes of interest from which localized ${ }^{1} \mathrm{H}$ MRS spectra were obtained. Spectra were also acquired from similar contralateral regions (see Fig. 4).

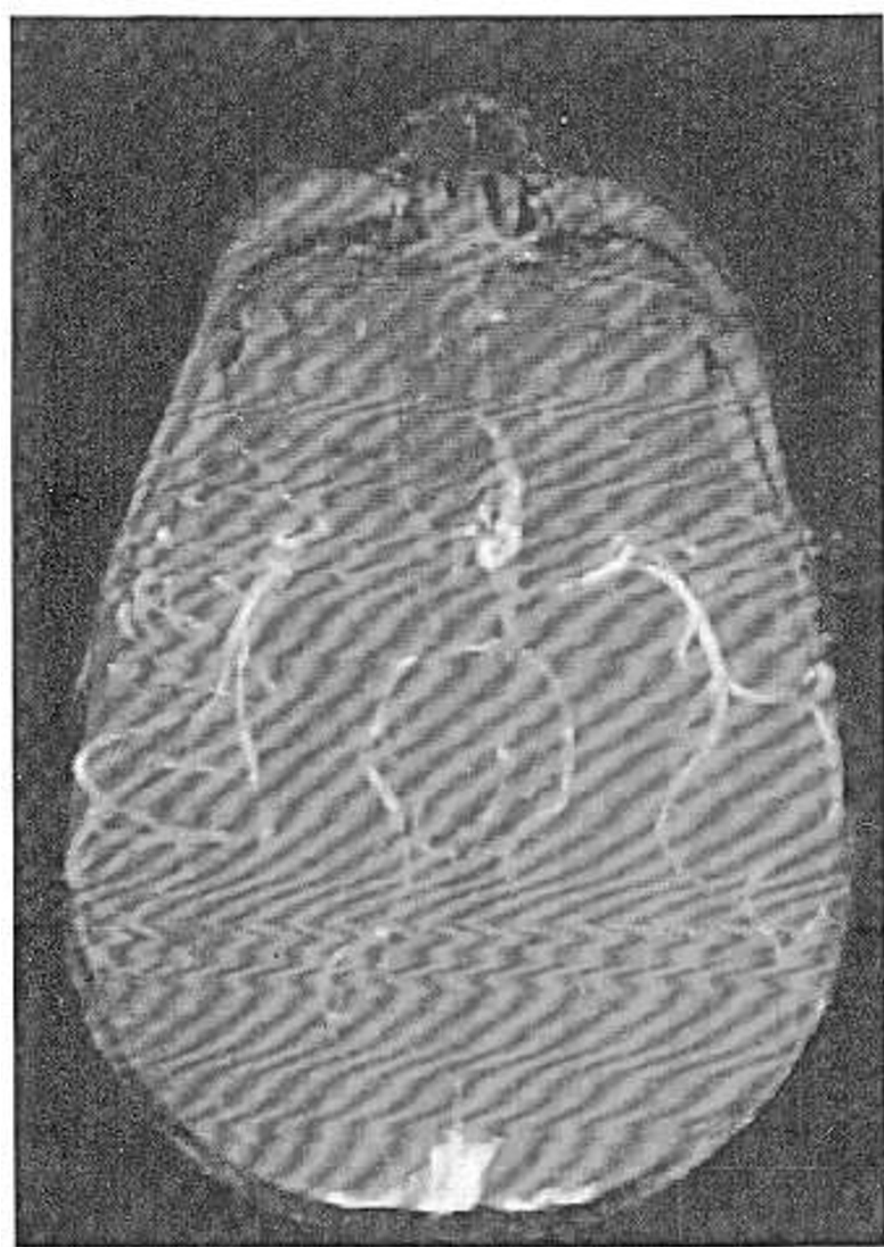

Fig. 2. MR angiogram obtained from case 1 at presentation. The left side appears normal. On the right, the internal carotid and middle cerebral arteries are patent, but there are prominent superficial vessels.

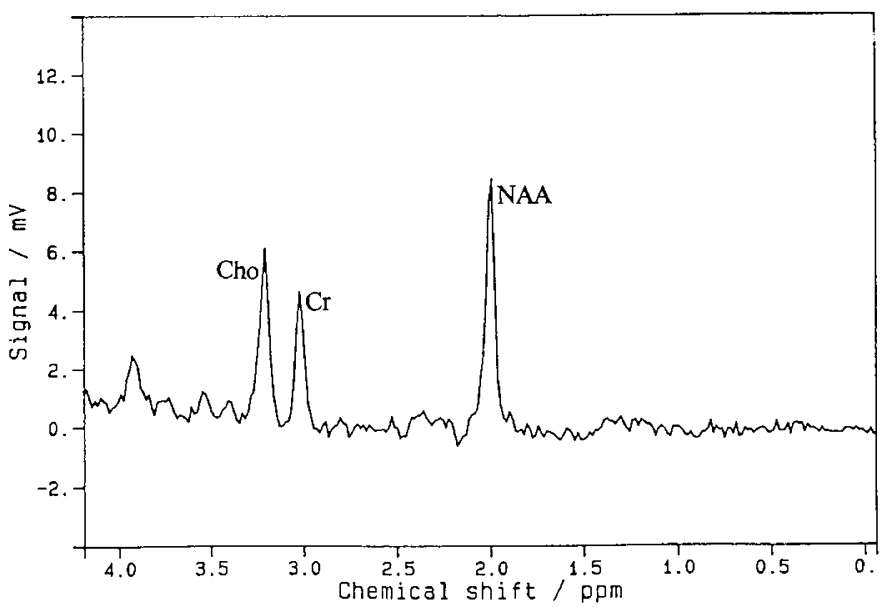

Fig. 3. Normal 'H MRS spectrum from a 12-mo-old girl, showing signals from NAA, Cr, and Cho.

abnormalities have been recognized previously $(21,22)$ and neurologic outcome appears to be related to the number of encephalopathic episodes (23). The mechanisms underlying the encephalopathy, however, have not been fully elucidated. Imaging of the brain during acute encephalopathy often shows widespread cerebral edema (22), and it is difficult to explain why some areas of the brain are more affected than others.

Ammonia is converted in the brain to glutamine by the enzyme glutamine synthetase with consumption of ATP. The enzyme is mainly found in astrocytes, and there is regional variation within the brain, with greater activity in the gray matter of the cerebral cortex than in the brain stem $(6,11)$. High plasma ammonia levels would lead to an accumulation of glutamine with astrocytes, and it has been proposed that the consequent osmotic effect causes astrocytes to swell with subsequent cerebral edema (1). Such astrocytic swelling has been demonstrated in vitro in experimentally induced hyperammonemia in rats (6) but has not yet been correlated with cerebral glutamine concentration.

The cerebrospinal fluid level of glutamine in hyperammonemic coma in OCT deficiency has been shown to be extremely 

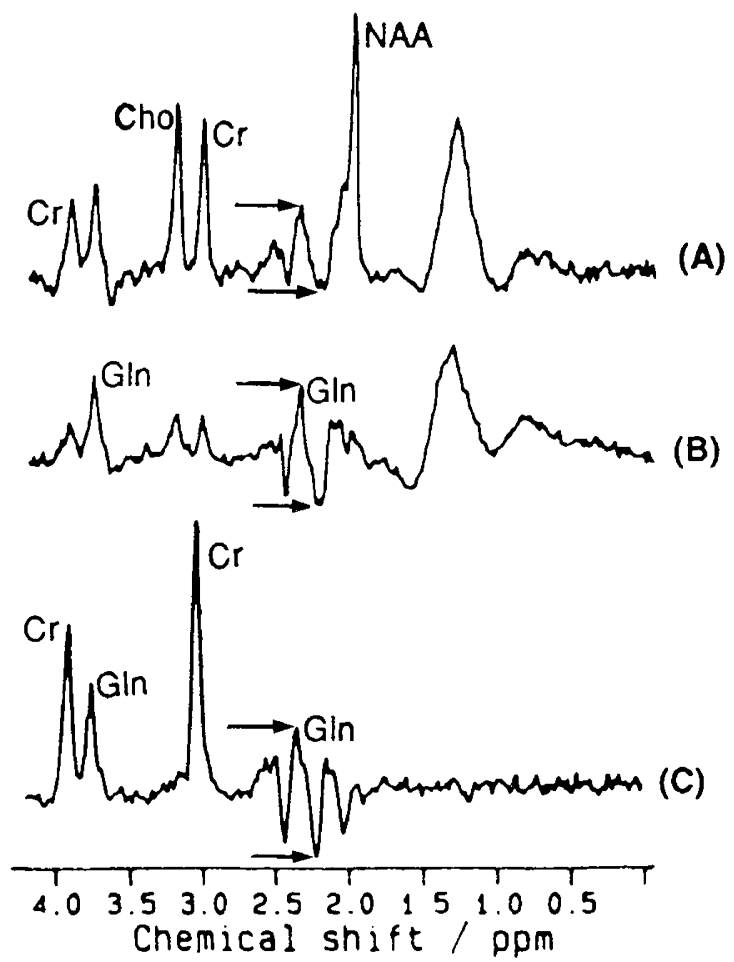

Fig. 4. ${ }^{1} \mathrm{H}$ MRS spectra obtained from case 1 and from a solution containing glutamine and creatine. The in vivo spectra were obtained at the time of presentation $(B)$ from the abnormal side and $(A)$ from a contralateral region (see Fig. 1 for location of regions). Signals are observed from NAA, $\mathrm{Cr}$, Cho, and glutamine $(G l n)$. For comparison, $C$ shows a spectrum obtained from a phantom containing $10 \mathrm{mM}$ creatine and $40 \mathrm{mM}$ glutamine in deuterium oxide. The signal centered at 1.5 ppm is from fats that can contribute to the spectra as contaminating signal from the scalp and bone marrow, which have very high lipid concentrations. The glutamine signal at $2.0-2.5 \mathrm{ppm}$ is measured from the peak-to-peak height as shown by the arrows.

high $(6.3 \mathrm{mmol} / \mathrm{L}$, normal $0.75 \pm 0.14)(24)$. The concentration of glutamine within brain tissue, however, has been difficult to measure. In this study, we have shown that brain glutamine is raised. Our data acquisition conditions were those that we routinely use in our clinical ${ }^{1} \mathrm{H}$ MRS studies, indicating that short $\mathrm{TE}$ are not essential for the detection of glutamine. In acute encephalopathy, the average of four measurements in two children is $13 \mathrm{mmol} / \mathrm{kg}$ wet weight, which is similar to values of brain glutamine obtained in postmortem studies of patients who had died from hepatic failure (25), and four times the values given for normal human brain tissue (26). As described in Materials and Methods, our measurements give a lower limit for the brain glutamine concentration. The actual concentrations within the brain are likely to be considerably higher, possibly by $50-100 \%$, and could be even greater in the astrocytes, where the glutamine is synthesized.

The reduction in the NAA, $\mathrm{Cr}$, and Cho signals seen in the first spectrum from the affected side in case 1 showed that there had already been extensive loss of cells within 2 wk of onset of symptoms. The degree of cerebral swelling and subsequent brain damage may be directly related to glutamine levels that were higher on the affected side in case 1 and on the side with the more marked abnormality in the visual evoked potentials in case 2. More extensive studies combining MR imaging, spectroscopy, and angiography could clarify the mechanisms underlying the focal nature of the brain damage.

In conclusion, we have used the noninvasive method of ${ }^{1} \mathrm{H}$ MRS to demonstrate very high cerebral glutamine concentrations in two patients with hyperammonemic encephalopathy secondary to OCT deficiency. This provides further support to the view that elevated glutamine may be an important factor in the development of hyperammonemic encephalopathy.

Acknowledgments. The authors thank Drs. R.A. Iles and S. Burns of the London Hospital Medical College for nuclear magnetic resonance analysis of urine.

\section{REFERENCES}

1. Brusilow SW, Horwich AL 1989 Urea cycle enzymes. In: Scriver CR, Beaudet AL, Sly WS, Valle D (eds) The Metabolic Basis of Inherited Disease, Vol 1 , 6th Ed. McGraw-Hill, New York

2. Batshaw ML, Msall M, Beaudet AL, Trojak J 1986 Risk of serious illness in heterozygotes for ornithine transcarbamylase deficiency. J Pediatr 108:236241

3. Surtees R, Leonard JV 1989 Acute metabolic encephalopathy: a review of causes, mechanisms and treatment. J Inherited Metab Dis 12(suppl 1):4254

4. Duffy TE, Plum F, Cooper AJL 1983 Cerebral ammonia metabolism in vivo. In: Glutamine, Glutamate, and GABA in the Central Nervous System. Alan R Liss, New York, pp 371-388

5. Colombo JP 1987 Urea cycle disorders, hyperammonaemia and neurotransmitter changes. Enzyme 38:214-219

6. Voorhies TM, Ehrlich ME, Duffy TE, Petito CK, Plum F 1983 Acute hyperammonemia in the young primate: physiologic and neuropathologic correlates. Pediatr Res 17:970-975

7. Breningstall GN 1986 Neurologic syndromes in hyperammonemic disorders. Pediatr Neurol 2:253-262

8. Chodobski A, Szmydynger-Chodobska J, Urbanska A, Szczepanska-Sadowska E 1986 Intracranial pressure, cerebral blood flow and cerebrospinal fluid formation during hyperammonemia in cat. J Neurosurg 65:86-91

9. Chodobski A, Szmydynger-Chodobska, Skolasinska K 1986 Effect of ammonia intoxication on cerebral blood flow, its autoregulation and responsiveness to carbon dioxide and papavarine. J Neurol Neurosurg Psychiatry 49:302309

10. Barzilay Z, Britten AG, Koehler RC, Dean JM, Traystman RJ 1985 Interaction of $\mathrm{CO}_{2}$ and ammonia on cerebral blood flow and $\mathrm{O}_{2}$ consumption in dogs. Am J Physiol 248:H500-H507

11. Cooper AJL, Vergara F, Duffy TE 1983 Cerebral glutamine synthetase. In: Glutamine, Glutamate, and GABA in the Central Nervous System. Alan R Liss, New York, pp 77-93

12. Fitzpatrick SM, Hetherington HP, Behar KL, Shulman RG 1989 Effects of acute hyperammonemia on cerebral amino acid metabolism and $\mathrm{pH}_{\mathbf{i}}$ in vivo, measured by ${ }^{1} \mathrm{H}$ and ${ }^{31} \mathrm{P}$ nuclear magnetic resonance. $\mathrm{J}$ Neurochem $52: 741$ 749

13. Bates TE, Williams SR, Kauppinen RA, Gadian DG 1989 Observations of cerebral metabolites in an animal model of acute liver failure. $J$ Neurochem 53:102-110

14. Bosman DK, Deutz NEP, de Graaf AA, Vd Hulst RWN, Van Ejik HMH, Bovee WMMJ, Maas MAW, Jorning GGA, Chamuleau RAFM 1990 Changes in brain metabolism during hyperammonemia and acute liver failure: results of a comparative ${ }^{1} \mathrm{H}$ NMR spectroscopy and biochemical investigation. Hepatology 12:281-290

15. Kreis R, Ross BD, Farrow NA, Ackerman Z 1992 Metabolic disorders of the brain in chronic hepatic encephalopathy detected with H-1 MR spectroscopy. Radiology 182:19-27

16. Shepherd JK, Hall-Craggs MA, Finn JP, Bingham RM 1990 Sedation in children scanned with high field magnetic resonance; the experience at the Hospital for Sick Children, Great Ormond Street. Br J Radiol 63:794-797

17. Finn JP, Connelly A, Atkinson D 1989 A modified inversion recovery sequence for routine high contrast brain imaging. 8th Annual Meeting of the Society of Magnetic Resonance Medicine, Amsterdam, p 772(abstr)

18. Ordidge RJ, Bendall MR, Gordon RE, Connelly A 1985 Volume selection for in vivo spectroscopy. In: Gorvind, Khatrapal, Saran (eds) Magnetic Resonance in Biology and Medicine. Tata-McGraw-Hill, New Delhi, India, pp 387-397

19. Klose U 1990 In vivo proton spectroscopy in presence of eddy currents. Magn Reson Med 14:23-60

20. Austin SJ, Connelly A, Gadian DG, Benton JS, Brett EM 1991 Localised ${ }^{1} \mathrm{H}$ NMR spectroscopy in Canavan's disease: a report of two cases. Magn Reson Med 19:439-445

21. de Grauw TJ, Smit LME, Brockstedt M, Meijer Y, v d Klei-v Moorsel J, Jakobs C 1990 Acute hemiparesis as the presenting sign in a heterozygote for ornithine transcarbamylase deficiency. Neuropediatrics 2:133-135 
22. Kendall BE, Kingsley DPE, Leonard JV, Lingham S, Oberholzer VG 1983 Neurological features and computed tomography of the brain in children with ornithine carbamoyl transferase deficiency. J Neurol Neurosurg Psychiatry 46:28-34

23. Msall M, Batshaw ML, Suss R, Brusilow SW, Mellits ED 1984 Neurological outcome in children with inborn errors of urea synthesis: outcome of urea cycle enzymopathies. N Engl $\mathbf{J}$ Med 310:1500-1505

24. Levin B, Abraham JM, Oberholzer VG, Burgess EA 1969 Hyperammonaemia: a deficiency of liver ornithine transcarbamylase: occurrence in mother and child. Arch Dis Child 44:152-169

25. Record CO, Buxton B, Chase RA, Curzon G, Murray-Lyon IM, Williams R 1976 Plasma and brain amino acids in fulminant hepatic failure and their relationship to hepatic encephalopathy. Eur J Clin Invest 6:387-394

26. Perry TL, Berry K, Hansen S, Diamond S, Mok C 1971 Regional distribution of amino acids in human brain obtained at autopsy. J Neurochem 18:513519

\section{Announcement}

In view of the appalling events that have occurred in Somalia in the past several months, there is a recognized need in Somalia for medical expertise at the most basic level of pediatric and nutritional care. Moreover, this need is likely to exist for months and even years beyond resolution of the political and social events presently taking place.

Accordingly, you are being asked to join in a volunteer effort to provide medical care to an entire generation of infants and children in Somalia. Due to the current civil unrest in that country, there is no intent to begin provision of such care until order is restored. However, to avoid undue delay at that time, we are asking now for the names of volunteers. By organizing now, it will be possible to mount a meaningful effort within days that might otherwise require months. Because there are thousands of deaths weekly in Somalia, by starting now we may be able to save many thousands of children who will undoubtedly die without us.

Because it is likely that the need for our services will extend beyond a 12-month period, volunteers for 1 to 4 months (or longer), as schedules permit, within the next 24-month period will be gratefully accepted.

For more information, please contact: Karl S. Roth, M.D., or Festus O. Adebonojo, M.D., Department of Pediatrics, Medical College of Virginia, Childrens Medical Center, Box 239, Richmond, VA 23298-0239. 
22. Kendall BE, Kingsley DPE, Leonard JV, Lingham S, Oberholzer VG 1983 Neurological features and computed tomography of the brain in children with ornithine carbamoyl transferase deficiency. J Neurol Neurosurg Psychiatry 46:28-34

23. Msall M, Batshaw ML, Suss R, Brusilow SW, Mellits ED 1984 Neurological outcome in children with inborn errors of urea synthesis: outcome of urea cycle enzymopathies. N Engl $\mathrm{J}$ Med 310:1500-1505

24. Levin B, Abraham JM, Oberholzer VG, Burgess EA 1969 Hyperammonaemia: a deficiency of liver ornithine transcarbamylase: occurrence in mother and child. Arch Dis Child 44:152-169

25. Record CO, Buxton B, Chase RA, Curzon G, Murray-Lyon IM, Williams R 1976 Plasma and brain amino acids in fulminant hepatic failure and their relationship to hepatic encephalopathy. Eur J Clin Invest 6:387-394

26. Perry TL, Berry K, Hansen S, Diamond S, Mok C 1971 Regional distribution of amino acids in human brain obtained at autopsy. J Neurochem 18:513519

\section{Announcement}

In view of the appalling events that have occurred in Somalia in the past several months, there is a recognized need in Somalia for medical expertise at the most basic level of pediatric and nutritional care. Moreover, this need is likely to exist for months and even years beyond resolution of the political and social events presently taking place.

Accordingly, you are being asked to join in a volunteer effort to provide medical care to an entire generation of infants and children in Somalia. Due to the current civil unrest in that country, there is no intent to begin provision of such care until order is restored. However, to avoid undue delay at that time, we are asking now for the names of volunteers. By organizing now, it will be possible to mount a meaningful effort within days that might otherwise require months. Because there are thousands of deaths weekly in Somalia, by starting now we may be able to save many thousands of children who will undoubtedly die without us.

Because it is likely that the need for our services will extend beyond a 12-month period, volunteers for 1 to 4 months (or longer), as schedules permit, within the next 24-month period will be gratefully accepted.

For more information, please contact: Karl S. Roth, M.D., or Festus O. Adebonojo, M.D., Department of Pediatrics, Medical College of Virginia, Childrens Medical Center, Box 239, Richmond, VA 23298-0239. 